Çukurova Üniversitesi Mühendislik Mimarlık Fakültesi Dergisi, 30(1), 209-214 ss., Haziran 2015

Çukurova University Journal of the Faculty of Engineering and Architecture, 30(1), pp. 209-214, June 2015

\title{
Basınçlı Hava Sistemlerinde Oluşan Hava Kaçaklarının Enerji Maliyetine Etkisinin Deneysel Olarak İncelenmesi
}

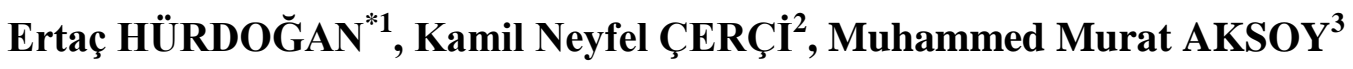 \\ Osmaniye Korkut Ata Üniversitesi, Mühendislik Fakültesi, Enerji Sistemleri Mühendisliği \\ Bölümü, Osmaniye
}

Geliş tarihi: 21.04 .2015

Kabul tarihi: 25.06 .2015

\section{Özet}

Enerji kaynaklarının tükenebilir oluşu, dışa bağımlılığın varlığı ve çevresel etkiler sebebiyle; günümüzde ülkeler için güvenli, yeterli miktarda, ucuz ve temiz enerji üretmek, ekonomik ve sosyal hayatın temel problemleri arasında yerini almaktadır. Sanayisi, ekonomisi ve nüfusu ile hızla büyümekte olan ülkemizde, buna paralel olarak enerji ihtiyacı sürekli artmaktadır. Enerji talebinin çok fazla olmasından dolayı enerji arzı, tasarruflu ve yenilenebilir enerji kaynakları ile bütünleşmelidir. Enerjinin en çok kullanıldığı alanlar endüstri ve binalardır. Basınçlı hava özellikle endüstride yaygın bir şekilde kullanılmaktadır. Bu çalışma kapsamında basınçlı hava sistemlerinde oluşan hava kaçaklarının enerji maliyetlerine etkisi deneysel olarak araştırılmıştır. Deneyler farklı basınç ve kaçak miktarlarında gerçekleştirilmiştir. Yapılan çalışma sonunda, hava kaçak miktarı artışının sistemin enerji tüketimini önemli oranda arttırdığı ayrıca bu artışın yüksek basınçta daha fazla olduğunu tespit edilmiştir.

Anahtar Kelimeler: Enerji tasarrufu, Basınçlı hava, Hava kaçağı

\section{Experimental Investigation of the Effect of Air Leakage occurs in Compressed Air System on Energy Costs}

\begin{abstract}
Nowadays, secure, sufficient quantity, cheap and clean energy produce takes its place among the main problems of economic and social life, due to consists of exhaustible energy resources, the presence of external dependence and environmental impacts. Likewise in our country with a rapidly growing industry, economy and population, the energy demand is constantly increasing. Due to a lot of energy demand, the energy supply must be integrated with saving and renewable energy sources. Energy is widely used in industry and buildings. Compressed air is extensively used in industry. In this study, the impact on energy costs of air leaks which occur in the compressed air system was experimentally investigated. Experiments were carried out at different amounts of pressure and air leakage. As a result of study, it was found that energy consumption of the system significantly increases with the increase of air leakage and pressure.
\end{abstract}

Keywords: Energy conservation, Compressed air, Air leakage

\footnotetext{
* Yazışmaların yapılacağı yazar: Ertaç HÜRDOĞAN, Osmaniye Korkut Ata Ü. Mühendislik Fakültesi, Enerji Sistemleri Mühendisliği Bölümü, Osmaniye. ehurdogan@osmaniye.edu.tr
} 


\section{GİRIŞ}

Enerji tüketiminin günümüzde maliyetleri çok artırdığı gerçeği, tüketicilerin bu konuda bazı önlemler almasını gerektirmektedir. Artan nüfus ve küresel 1sınma, sürdürülebilir ve yenilenebilir enerji kaynaklarına verilen önemin artmasına sebep olmuştur [1]. Dünyadaki nüfus artışı, uzun dönemde ortalama \%3,5 büyümesi beklenen dünya ekonomisi, sanayileşme ve kentleşme, doğal kaynaklara ve enerjiye olan talebi önemli ölçüde arttırmaktadır. Yapılan projeksiyon çalışmaları, mevcut enerji politikalarının devamı halinde, 2035 yılında dünya enerji talebinin, ortalama yıllık $\% 1,5$ 'lik artışla, 2010 yılına göre \%46,7 (12.730 milyon ton eşdeğeri petrolden (MTEP) 18.676 MTEP'e) daha fazla olacağına işaret etmektedir [2]. Küresel enerji tüketiminin ise, 2035 y1lına gelindiğinde 1998 yılında tüketilen enerji miktarının iki katı, 2055 yılında ise üç katı olacağı tahmin edilmektedir [3]. Bu sebeple, kullanılan enerji çeşidi yenilenebilir ya da fosil temeline dayalı olup olmadığına bakılmaksızın, enerjinin verimli bir şekilde kullanılması gerekmektedir.

Bilindiği gibi ülkemizde enerji kullanımı sanayi (endüstri), binalar (ticari ve konut) ve ulaştırma olmak üzere üç ana grupta gerçekleştirilmektedir. Bunlardan sanayi sektörü, ülkemizdeki nihai enerji tüketimi içindeki yaklaşık \%36 ve elektrik tüketimindeki \%55 düzeyindeki payı ile önemli bir yere sahiptir. Sanayi sektörü, gerek yüksek enerji tasarruf potansiyeline sahip olması, gerekse de sanayide tüketilen enerjinin çoğunlukla ticari enerji olması hasebiyle enerji tasarrufu çalışmalarında öncelikle ele alınması gereken bir sektördür.

Endüstrideki toplam enerji kullanımının yaklaşık \%10'unu basınçlı hava sistemleri oluşturmaktadır [1]. Basınçlı hava, dış ortamdan alınan havanın bir kompresörde belli oranda sıkıştırılmasıyla elde edilir. Basınçlı hava uygun, güvenli ve emniyetli olduğu için, bir güç kaynağı olarak kontrol vanalarında, hava motorlarında, temizleme amaçlı olarak hava tabancalarında ve daha birçok yerde yaygın olarak kullanılmaktadır. Patlamalara ve aşırı yüke karşı dayanıklı olmaları, sıcaklık, nem, toz ve elektromanyetik gürültü gibi unsurlardan etkilenmemeleri, bakımlarının kolay olmasından dolayı basınçlı hava sistemleri endüstride çok sık kullanılan sistemlerin başında gelmektedir $[1,4]$. Çizelge 1'de farklı endüstriyel uygulamalarda basınçlı havanın kullanım alanları gösterilmiştir [5].

Çizelge 1. Basınçlı havanın kullanıldığı sektörler

\begin{tabular}{|c|c|}
\hline $\begin{array}{l}\text { Endüstri } \\
\text { Türleri }\end{array}$ & $\begin{array}{l}\text { Basınçlı Havanın } \\
\text { Kullanıldığı Alanlar }\end{array}$ \\
\hline $\begin{array}{l}\text { Tekstil \& } \\
\text { Konfeksiyon }\end{array}$ & $\begin{array}{l}\text { Taşıma, Sıkıştırma, Tahrik ve } \\
\text { Kontrol, Dokuma Tezgâhı, } \\
\text { Tekstüre, İplik Çekme }\end{array}$ \\
\hline $\begin{array}{l}\text { Plastik \& } \\
\text { Ambalaj }\end{array}$ & $\begin{array}{l}\text { Kalıplama, Sıkıştırma, Tahrik } \\
\text { ve Kontrol, Presleme, } \\
\text { Enjeksiyon Kalıplama }\end{array}$ \\
\hline Petro-Kimya & $\begin{array}{l}\text { Gaz sıkıştırma, Taşıma, Tahrik } \\
\text { ve Kontrol }\end{array}$ \\
\hline $\begin{array}{l}\text { Kâğlt \& } \\
\text { Kereste }\end{array}$ & $\begin{array}{l}\text { Taşıma, Tahrik ve Kontrol, } \\
\text { Testere ile Kesme }\end{array}$ \\
\hline $\begin{array}{l}\text { Maden \& } \\
\text { Demir-Çelik }\end{array}$ & 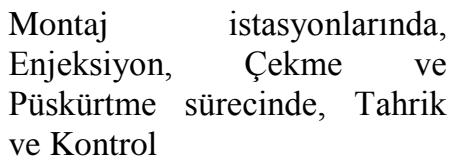 \\
\hline Gıda & $\begin{array}{l}\text { Dehidrasyon } \\
\text { Şişeye doldurma, Püskürtme } \\
\text { ile kaplama, Temizleme, } \\
\text { Taşıma, Tahrik ve Kontrol, } \\
\text { Vakumla paketleme }\end{array}$ \\
\hline $\begin{array}{l}\text { Toprak (Taş, } \\
\text { Kil ve Cam) } \\
\text { Ürünleri }\end{array}$ & $\begin{array}{l}\text { Taşıma, Harmanlama, } \\
\text { Karıştırma, Soğutma, Cam } \\
\text { üfleme, Kalıplama, Tahrik ve } \\
\text { Kontrol }\end{array}$ \\
\hline
\end{tabular}

Basınçlı hava sistemlerinde harcanan enerjide alınabilecek bazı önlemler sayesinde \%20 ile \%50 arasında tasarruf etmek mümkündür [5,6]. Basınçlı hava sistemleri için ekonomik ve teknik açıdan uygulanabilir tasarruf oranları Şekil 1'de gösterilmiştir. Şekilden de görüldüğü gibi basınçlı hava sistemlerinde meydana gelen hava kaçaklarının giderilmesiyle enerjiden \%42 oranında tasarruf etmek mümkün olabilmektedir [7,8]. Üretilen basınçlı havanın \%20 ile \%30'u 
Sızıntılardan dolayı kaybolmaktadır [1,9]. Hava kaçakları genellikle bağlantı noktaları, flanşlarda, redüksiyonlarda, manşonlarda, dirseklerde, tahliye -çek valflerinde, filtrelerde ve basınçlı havayı kullanan cihazlarda meydana gelmektedir. Hava kaçakları oluşmasında, sistem tasarımı ve eksik bakımdan kaynaklanan başlıca iki sebep bulunmaktadır. Hava kaçaklarından dolayı gerçekleşen enerji kaybı, sadece maliyetin artmasına değil aynı zamanda sistem basıncının gereksiz yere düşmesine ve bu tür sistemlerde kullanılan pnömatik donanımların daha az verimle çalışarak çalışma ömürlerinin kısalmasına yol açmaktadır. Ayrıca hava kaçaklarından dolayı daha uzun süreli bakım-servis gereksinimi ve yetersiz kalan kompresörden dolayı fazladan kapasite artırımı yapılmaktadır [10].

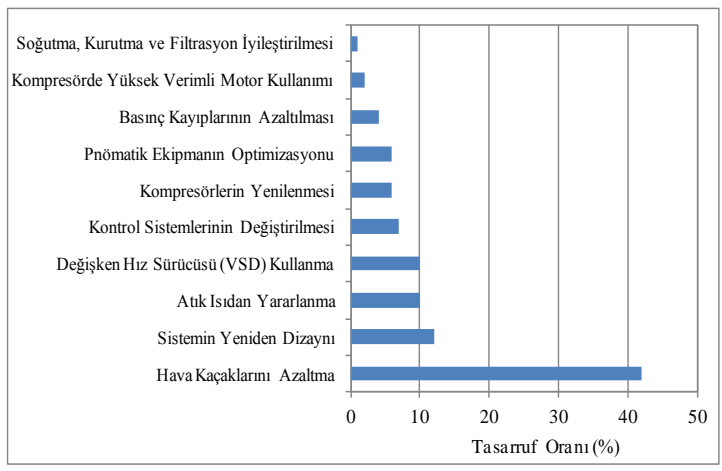

Şekil 1. Basınçlı hava sistemlerinde ekonomik ve teknik açıdan uygulanabilir tasarruf miktarları $[7,8]$.

Şekil 1'den yine görülebileceği gibi basınçlı hava sistemlerinde, hava kaçaklarının azaltılmasının dışında alınabilecek diğer bazı tasarruf önlemleri düşük basınçlı hava kullanılması, yüksek verimli motorların (değişken hız sürücülü) kullanılması ve atık ısıdan geri kazanım yapılmasıdır. Sistemde basınçlandırılacak havanın giriş sıcaklığı bu tür sistemlerde büyük önem arz etmektedir. Giriş hava sıcaklığında her $5^{\circ} \mathrm{C}$ 'lik düşüş enerji tüketiminde \%2'lik bir azalmaya sebep olduğundan, kompresör giriş havasının soğuk olması sağlanmalıdır [9]. Basınçlı hava sistemlerinin mümkün olan en düşük basınçta çalıștırılması ile yüksek basınçtan dolayı olabilecek hava kaçaklarını azaltmasının yanı sıra basıncın yükselmesi ile tüketilecek enerjinin de artması engellenebilmektedir.

$\mathrm{Bu}$ çalışma kapsamında Osmaniye Korkut Ata Üniversitesi Enerji Eğitim-Etüt Uygulama ve Araştırma Merkezi (OKÜ ENERMER) Enerji Verimliliği Laboratuvarında bulunan basınçlı hava sistemi kullanılarak deneyler gerçekleştirilmiştir. Yapılan çalışma ile hava kaçaklarının sistemin enerji tüketimine etkisi araştırılmıştır.

\section{SISTEM TANITIMI}

OKÜ ENERMER bünyesinde bulunan basinçlı hava sisteminin şematik resmi ve görünümü Şekil 2 ve 3 'te görülmektedir. Sistemi oluşturan ana elemanlar kompresör, kurutucu, hava tank1, filtrelerdir. Kompresör (I) tarafindan ortamdan emilen hava, öncelikle kompresör hava tankında (II) istenilen basınç değeri elde edilene kadar sıkıştırılmaktadır. Sistemde kompresör hava tankı kompresörün ani değişimleri söz konusu olduğunda regülasyon için kullanılmaktadır. Tank içerisinde basıncı ve sicaklığı çok yüksek hava bulunmaktadır. Bu havayı soğutmak ve nemini düşürerek kalitesini arttırmak için basınçlı hava daha sonra bir kurutucudan (V) geçirilmektedir. Basınçlı hava tank çıkışında beraberinde tank yüzeyinde meydana gelen paslanmalardan kaynaklı kirletici maddelerde getirerek kurutucu içerisindeki eşanjörün tıkanmasına sebep olabilmektedir. $\mathrm{Bu}$ sorunu gidermek için hava kurutucuya girmeden önce bir filtreden (IV) geçirilmektedir. Kurutucuda nemi ve sıcaklığg düşürülmüş olan basınçlı hava çıkışta ikinci bir filtreden geçirilmektedir. Bunun sebebi ise, kurutucuya basınçlı hava ile birlikte girebilecek buharlaşmış yağın ileriye taşınmasını engellemektir. Filtrede yağdan arındırılan basınçlı hava dağıtım hattı yardımıla asıl basınçlandırılmak istenen ikinci bir tanka iletilir. Dağıtım hattında kullanılan basınçlı havanın debisi hat üzerinde bulunan debi ölçer (VI) yardımıyla ölçülmektedir. İkinci tankın dolum işlemi gerçekleştikten sonra basınçlı hava, manifold üzerinden geçerek kullanılmak istenen yere gönderilmektedir. Sistemde manifold (VII) hava kaçaklarını temsil etmek için kullanılmıştır. Hat üzerinde farklı miktarlarda kaçak yaratmak için 
manifold üzerinde 1,2 ve 4 mm'lik delikler yer almaktadır. Çizelge 2'de basınçlı hava sisteminde kullanılan cihazlar ve özellikleri verilmiştir.

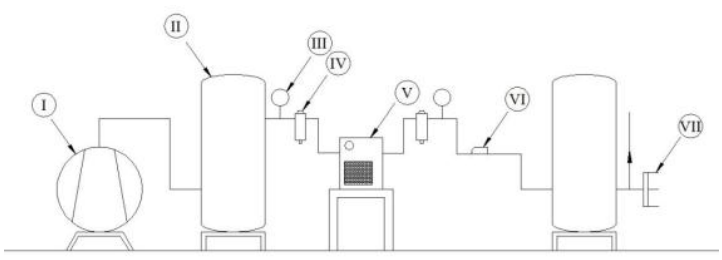

Şekil 2. Basınçlı hava sisteminin şematik resmi, (I) Kompresör, (II) Tank, (III) Manometre, (IV) Filtre, (V) Kurutucu, (VI) Debi Ölçer, (VII) Manifold

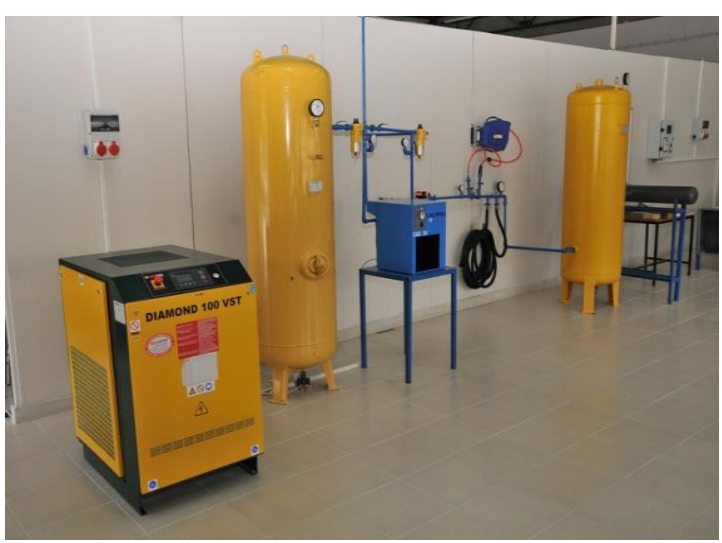

Şekil 3. OKÜ ENERMER laboratuvarında bulunan basınçlı hava sisteminin resmi

Çizelge 2. Basınçlı hava sisteminde kullanılan cihazlar ve özellikleri

\begin{tabular}{|c|c|c|}
\hline Cihaz & Marka & Teknik özellikler \\
\hline Kompresör & Ekomak & $\begin{array}{l}\text { Deplasmanlı (Vidalı) } \\
\text { Çalışma bas.: } 8 \text { bar } \\
\text { Debi: } 1100 \text { lt/dk } \\
\text { Motor Gücü: } 7,5 \mathrm{~kW}\end{array}$ \\
\hline Kurutucu & Calypso & $\begin{array}{l}\text { Is1 pompası } \\
\text { Max. Çalış.Bas.: } 16 \text { bar } \\
\text { Kapasite: } 1,8 \mathrm{~m}^{3} / \mathrm{dk} \\
\text { Komp. Gücü: } 0,28 \mathrm{~kW}\end{array}$ \\
\hline Debi Ölçer & Dwyer & $\begin{array}{l}\text { Max. Çalış.Bas.: } 16 \text { bar } \\
\text { Çalışma Sic.: } 0-60^{\circ} \mathrm{C} \\
\text { Çalışma Gerilimi: } 24 \mathrm{~V}\end{array}$ \\
\hline $\begin{array}{l}\text { Hava } \\
\text { Tank1 }\end{array}$ & $\begin{array}{l}\text { Teknik } \\
\text { Bombe }\end{array}$ & $\begin{array}{l}\text { Çalışma Basıncı: } 11 \\
\text { bar Kapasite: } 500 \text { Lt. }\end{array}$ \\
\hline
\end{tabular}

\section{HESAPLAMALAR}

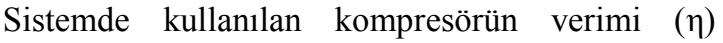
Eşitlik (1) kullanılarak hesaplanmaktadır [9].

$\eta=\frac{\mathrm{W}_{\text {teorik }}}{\mathrm{w}} \times 100 \quad(\%)$

Burada "W" kompresörün çektiği gücü, $\mathrm{W}_{\text {teorik }}$ ise teorik şaft gücünü ifade etmektedir. W kompresör üzerinde bulunan ekrandan okunarak belirlenmekte, $\mathrm{W}_{\text {teorik }}$ ise aşağıdaki eşitlik ile hesaplanmaktadır [9].

$\mathrm{W}_{\text {teorik }}=\frac{(\mathrm{n}+1) \times \mathrm{k}}{\mathrm{k}-1} \times \frac{\mathrm{P}_{\mathrm{s}} \times \mathrm{Q}_{\mathrm{s}}}{0,06} \times\left\{\left(\frac{\mathrm{P}_{\mathrm{hat}}}{\mathrm{P}_{\mathrm{s}}}\right)^{\frac{(\mathrm{k}-1)}{(\mathrm{n}+1) \times \mathrm{k}}}-1\right\}(\mathrm{kW})$

Eşitlik (2)'de n düzenleme faktörü (tek kademeli sıkıştırma için), $\mathrm{k}$ özgül 1sı oranını, $\mathrm{P}_{\mathrm{s}}$ emme basıncını (deneylerde kompresör tarafından emilen basınç, atmosfer basıncına eşit olarak alınmıştır $\left.\left(\mathrm{P}_{\mathrm{s}}=\mathrm{P}_{\mathrm{atm}}=101.3 \mathrm{kPa}\right)\right), \mathrm{Q}_{\mathrm{s}}$ basınçlı hava debisini, $\mathrm{P}_{\text {hat }}$ hat basincı ifade etmektedir.

Hava kaçaklarından dolayı sistemde meydana gelen güç kaybı ( $\mathrm{W}_{\text {kayp }}$ ) Eşitlik (3) yardımıyla hesaplanmaktadır [9].

$\mathrm{W}_{\text {kayip }}=\frac{(\mathrm{n}+1) \times \mathrm{k}}{\mathrm{k}-1} \times \frac{\mathrm{P}_{\mathrm{s}} \times \mathrm{Q}_{\mathrm{s}}}{0,06} \times\left\{\left(\frac{\mid \mathrm{P}_{\text {hat }}}{\mathrm{P}_{\mathrm{s}}}\right)^{\frac{(\mathrm{k}-1)}{(\mathrm{n}+1) \times \mathrm{k}}}-1\right\} \times \frac{\phi}{\eta_{\mathrm{m}} \times \eta_{\text {ad }}}(\mathrm{kW})$

Burada $\phi$ avans oranını, $\eta_{\mathrm{m}}$ mekanik verimi, $\eta_{\mathrm{ad}}$ adyabatik verimi ifade etmektedir. Çizelge 3'te yukarıda verilen eşitliklerde alınan bazı değerler verilmiştir.

Çizelge 3. Hesaplarda alınan değerler

\begin{tabular}{ccccc}
\hline $\mathbf{n}$ & $\mathbf{k}$ & $\boldsymbol{\phi}$ & $\boldsymbol{\eta}_{\boldsymbol{m}}$ & $\boldsymbol{\eta}_{\boldsymbol{a d}}$ \\
\hline 0 & 1,4 & 1,10 & 0,93 & 0,70 \\
\hline
\end{tabular}

\section{BULGULAR VE TARTIŞMA}

$\mathrm{Bu}$ çalışma kapsamında değerlendirilen basınçlı hava sisteminde, hava kaçaklarının sistemin enerji maliyeti üzerine etkisini belirlemek için deneyler gerçekleştirilmiştir. Deneylerde 6 ve 8 bar olmak üzere iki farklı basınç ve 3 farklı delik çapı kullanılmıştır. Deneyler gerçekleştirilirken sistem girişindeki havanın sicaklığı $21^{\circ} \mathrm{C}$ olarak 
ölçülmüştür. Çizelge 4'te sistemde kaçak olmaması durumunda sistemin performansinı belirlemek için gerçekleştirilen deneylerden elde edilen sonuçlar verilmiştir. Çizelgeden kompresör veriminin 6 ve 8 Bar'da sirasiyla \%4,5 ve \%6,3, tüketilen gücün ise sırasıyla 3 ve $3,5 \mathrm{~kW}$ olduğu görülmektedir. Çizelge 5'de aynı basınç değerlerinde 1,2 ve $4 \mathrm{~mm}$ delik çaplarında gerçekleştirilen deneylerden elde edilen sonuçlar verilmiştir. Çizelgeden 6 bar basınçta, $1 \mathrm{~mm}$ delik çapında oluşan güç kaybının $\left(\mathrm{W}_{\text {kayıp }}\right) 0,62 \mathrm{~kW}$ iken $4 \mathrm{~mm}$ delik çapındaki güç kaybının $5,3 \mathrm{~kW}$ olduğu dolayısıyla güç kaybının hava kaçak miktarındaki artışla (delik çapındaki artış) yaklaşık \%88 arttığı anlaşılmaktadır. Benzer sonuçlar 8 bar basınç için de elde edilmiştir. Çizelgeden ayrıca aynı delik çapında basıncın artmasıyla güç kaybının da arttığg görülmektedir. 6 bar'da $2 \mathrm{~mm}$ delik çapında güç kaybı 1,20 kW iken 8 bar'da güç kaybı 3,1 kW'dır. Yapılan deneyler sonucunda, hava kaçak miktarı artışının ele alınan basınçlı hava sistemindeki enerji tüketimini önemli oranda artırdığı ayrıca bu artışın yüksek basınçta daha fazla olduğunu tespit edilmiştir.

Çizelge 4. Sistemde kaçak olmaması durumda elde edilen sonuçlar

\begin{tabular}{ccccc}
\hline & \multicolumn{2}{c}{ Ölçülen } & \multicolumn{2}{c}{ Hesaplanan } \\
\hline $\begin{array}{c}\mathbf{P}_{\text {hat }} \\
(\mathbf{b a r})\end{array}$ & $\begin{array}{c}\mathbf{W} \\
(\mathbf{k W})\end{array}$ & $\begin{array}{c}\mathbf{Q}_{\mathbf{s}} \\
\left(\mathbf{N m}^{3} / \mathbf{d k}\right)\end{array}$ & $\begin{array}{c}\mathbf{W}_{\text {teorik }} \\
(\mathbf{k W})\end{array}$ & $\begin{array}{c}\boldsymbol{\eta} \\
(\boldsymbol{\%})\end{array}$ \\
\hline 6 & 3,0 & 0,035 & 0,137 & 4,56 \\
8 & 3,5 & 0,047 & 0,220 & 6,30 \\
\hline
\end{tabular}

Çizelge 5. Sistemde kaçak olması durumda elde edilen sonuçlar

\begin{tabular}{|c|c|c|c|c|c|c|}
\hline \multirow[b]{2}{*}{ 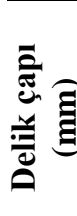 } & \multicolumn{3}{|c|}{6 Bar } & \multicolumn{3}{|c|}{8 Bar } \\
\hline & $3 \sum_{y}$ & Oิm & $\sum^{2}$ & 3 & Oำ & $\sum^{2}$ \\
\hline 1 & 3,6 & 0,085 & 0,62 & 4,4 & 0,189 & 1,80 \\
\hline 2 & 4,0 & 0,165 & 1,20 & 4,7 & 0,363 & 3,10 \\
\hline 4 & 5,0 & 0,743 & 5,30 & 7,0 & 1,080 & 9,20 \\
\hline
\end{tabular}

Elde edilen sonuçların gerçek çalıșma koşulları için de değerlendirilebilmesi amacıyla deneylerin gerçekleştirildiği sistemin endüstride yıllık 5000 saat çalıştığ düş̧ünülmüştür. Şekil 4'de basınç ve delik çapına göre yıllık kayıp miktarının değişimi verilmiştir. Şekilden de görüldüğü gibi kaçak miktarının ve basıncın artması yıllık tüketimin artması anlamına gelmektedir. Avrupa'da yer alan bir konut için ortalama elektrik enerjisi tüketimi y1llık $2700 \mathrm{kWh}$ olduğu düşünülürse [11], 8 bar'da ve $4 \mathrm{~mm}$ delik çapında oluşan enerji kaybı (46000 kWh) yaklaşık 17 konutun enerji ihtiyacına karşılık gelmektedir.

$\mathrm{Bu}$ sonuç basınçlı hava sistemlerinde hava kaçaklarının dikkate alınması gereken önemli bir sorun olduğunu ve enerji verimliliği açısından mutlaka giderilmesi gerektiğini göstermektedir.

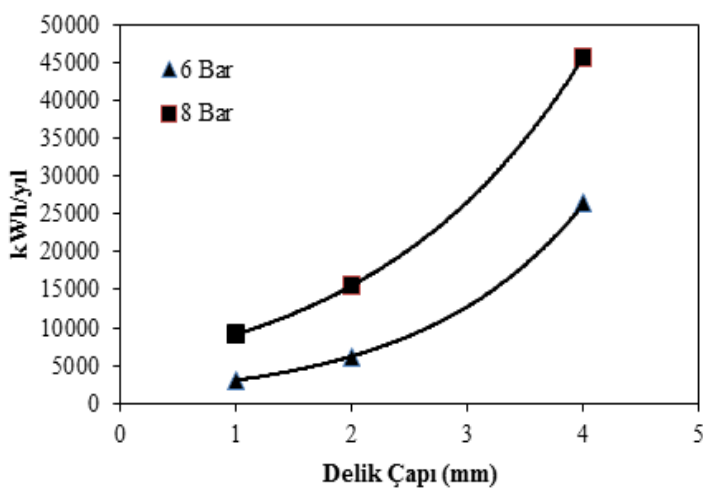

Şekil 4. Farklı delik çaplarında oluşan enerji kayıpları

\section{SONUÇ}

Endüstride yaygın olarak kullanılan sistemlerden biri basınçlı hava sistemleridir. $\mathrm{Bu}$ çalışma kapsamında bir basınçlı hava sistemi ele alınarak farklı basınç ve hava kaçak miktarlarında sistemde oluşabilecek enerji kayıpları araştırılmıştır. Yapılan çalışma sonunda, hava kaçak miktarı artışının sistemin enerji tüketimini önemli oranda arttırdığı ayrıca bu artışın yüksek basınçta daha fazla olduğunu tespit edilmiştir. Ayrıca bu çalışmayla basınçlı hava sistemlerinin düşük basınçta çalıştırılmasının önemi de ortaya konmuştur. 


\section{KAYNAKLAR}

1. Kaya, D., Phelan, P., Chau, D., Sarac, H.I., 2002. Energy Conservation in Compressed-Air Systems. International Journal of Energy Research, 26: 837-49.

2. TC. Enerji ve Tabii Kaynaklar Bakanlığı, 2014.http://www.enerji.gov.tr/index.php?sf=we bpages\&b=enerji, 17 Temmuz

3. TC. Dışişleri Başkanlığı, Yenilenebilir Enerji Kaynakları, http://www.mfa.gov.tr/yenilenebilir-enerjikaynaklari.tr.mfa, 11 Şubat 2015.

4. Karatas, A., 2013. Basınçlı Hava Sistemlerinde Enerji Verimliliği: Bir Çelik Fabrikasının Basınçlı Hava Denetleme Çalışması. Tesisat Mühendisliği, 14(48):20.

5. Saidur, R., Rahim, N.A., 2010. Hasanuzzaman, M., A Review on Compressed-Air Energy Use and Energy Savings, Renewable and Sustainable Energy Reviews, 14:1135-1153.

6. Talbott, E.M., 1993. Compressed Air Systems: a Guidebook on Energy and Cost Savings, Second Edition, the Fairmont Press.

7. Compressed Air System in the European Union, Energy, Emissions, Savings Potential and Policy Action, 2001.

8. Mckane, A., Mollet, J., Aylwin, R., Bertoldi, P., Cockburn, J., Cockrill, C., 2005. Imssa: Creating an International Standard for Motor Software, Energy Efficiency in Motor Drives, EEMODS 05, in Proceedings of the 4th International Conference.

9. Yenilenebilir Enerji Genel Müdürlüğü, Sanayide Enerji Yönetimi Esasları, Cilt III, 11. Bask1, 2009.

10. Cengel, Y.A., Shivaprasad, B.G., Tuner, R.H., Cerci, Y. 2000, Reduced Compressed Air Costs, Hydrocarbon Processing. 57-64, 2012.

11. Almeidaa, A., Fonsecab, P., Schlomannc, B., Feilbergd, N., 2011. Characterization of the Household Electricity Consumption in the EU, Potential Energy Savings and Specific Policy Recommendations, Energy and Buildings. 43:1884-1894. 